\title{
Stress Analysis of Non-Uniform Thickness Piping System with General Piping Analysis Software
}

Ming LI*, Manohar Lal AGGARWAL, Engineering Mechanics Department, Ontario Power Generation Inc., 889 Brock Road, Pickering, Ontario, Canada, L1W 3J2. Email: ming.li@opg.com

\begin{abstract}
Most general piping analysis software can only perform ASME design stage type code compliance analysis with uniform pipe wall thickness. However, non-uniform wall thickness, commonly on elbows or bends, can be found in many industrial applications. The non-uniform thickness caused by flow accelerated corrosion (FAC) or other similar factors could lead to thin region anywhere around the bends or elbows. In this paper, an analysis procedure is introduced to enable a general piping software to conduct ASME III class 1 piping analysis with non-uniform wall thickness. The demonstration is performed on CANDU (Canadian Deuterium Uranium) feeder pipes, which could be subject to FAC caused wall thinning on bends. The results are compared with both conventional uniform thickness piping analysis and non-uniform thickness solid finite element analysis. The comparison shows the validity of the proposed "average-minimum-average” approach which using the general piping analysis software. The approach remains conservative compared to the solid finite element results, yet it gives lower acceptable thickness than the conventional piping analysis. It is noted this approach is applicable to the thin region located anywhere at the bends.
\end{abstract}

\subsection{INTRODUCTION}

Most piping analysis software can only enable engineers and designers to perform piping stress analysis with nominal or uniform pipe wall thickness. It is an acceptable practice in the design of new construction. However, pipe wall thickness may be reduced during the operation service caused by various degradation mechanisms, such as FAC, or becomes non-uniform by the fabrication process. The later might be less critical due to sufficient design margin in the new design stage. However, the service condition caused wall thinning must be assessed to determine if the degraded pipe or fittings remain fit for safe service.

In CANDU nuclear power plant, feeder pipes carry heavy water to and from the reactor fuel channels to remove heat produced by the fission of uranium fuel. The feeder pipes connect the inlet and outlet headers to the reactor core. The number of feeder pipes is in the range of 760 to 960 for various types of CANDU designs. A typical feeder layout is shown in Figure 1. The feeders are made of SA106 Grade B carbon steel and range from 1.5 inch $(38 \mathrm{~mm})$ to $3.5 \mathrm{inch}(89 \mathrm{~mm})$ nominal pipe diameter, with lengths from 20 feet $(6.1 \mathrm{~m})$ to 60 feet $(18.3 \mathrm{~m})$. Feeder piping is designed to Class 1 piping requirements of the ASME Boiler and Pressure Vessel Code, Section III, Subsection NB and CSA Standards. A typical feeder has several bends between a header and a fuel channel. In general, the bends closest to the fuel channel connections represent the most critically stressed sections of the feeder pipes. Severe wall loss due to FAC has been found in CANDU stations, the wall thickness reduction is as high as the half of nominal wall values.

In general, wall thickness is non-uniformly distributed at cross sections of new feeder bends because of fabrication process, thinner at the extrados and thicker at cheeks and intrados. However, the thin region for in-service-bends can be anywhere at bends including near to intrados. The ratio of the maximum to the minimum wall thickness of serviced pipe bends often greatly exceeds the initial non-uniformity of a new pipe. Using the maximum or minimum thickness in piping analysis software could either underestimate or overestimate stresses at thinned bends. It is necessary to find the more realistic stress value in code compliance check for the disposition of a feeder bend.

An "average-minimum-average” approach is presented in this paper. In this approach, the average thickness is used to calculate loads or stiffness and moment of inertia, but the minimum thickness is used to calculate stress index.

The stress range in NB-3600 is presented in a general form below.

$$
\operatorname{Si}\left(\mathrm{T}_{\min }\right) * \frac{\mathrm{D}_{\mathrm{o}} * \mathrm{M}_{\mathrm{i}}\left(\mathrm{T}_{\text {avg }}\right)}{2 * \mathrm{I}\left(\mathrm{T}_{\text {avg }}\right)}
$$

where $\quad \mathrm{Si}-$ stress index $(\mathrm{B}, \mathrm{C}, \mathrm{K})$

$\mathrm{D}_{\mathrm{o}}$ - outside diameter of pipe

$\mathrm{M}_{\mathrm{i}}$ - resultant range of moment

I - moment of inertia

$\mathrm{T}_{\min }-$ minimum thickness at the bend cross section

$\mathrm{T}_{\mathrm{avg}}$ - average thickness at the bend cross section 
In the above expression, $\mathrm{Si}\left(\mathrm{T}_{\min }\right), \mathrm{M}_{\mathrm{i}}\left(\mathrm{T}_{\mathrm{avg}}\right), \mathrm{I}\left(\mathrm{T}_{\mathrm{avg}}\right)$ are functions of minimum and average thicknesses respectively.

In this approach, the average thickness $T_{\text {avg }}$ is input into piping software to calculate stiffness matrices, from which the moment loading $\mathrm{M}_{\mathrm{i}}$ in code equations are obtained. $\mathrm{T}_{\text {avg }}$ is also used to calculate moment of inertia, $\mathrm{I}$, used in code equations.

In Table NB - 3681(a)-1, among stress index (B,C and K) of curved pipe or welded elbows, only $\mathrm{B}_{1}, \mathrm{C}_{1}, \mathrm{~B}_{2}$ and $\mathrm{C}_{2}$ are functions of bend thickness [Reference 1]. In the proposed analysis method, primary stress indices $B_{1}, C_{1}$ are calculated using formulas given in NB-3683.7. The relation given by NB-3683.7 (b) for $C_{2}$ is known to be conservative, thus the stress index $C_{2}$ is determined by detail finite element analysis $\left(B_{2}=2 / 3 C_{2}\right)$.

A comparison of stress index $\mathrm{C}_{2}$ based on uniform and non-uniform thicknesses is conducted to verify that the use of the minimum thickness for $\mathrm{Si}$ is conservative. To illustrate the methodology, the non-uniform thickness of bends is represented, but not limited to, by a simplified thickness profile at bend cross section: a minimum thickness at the extrados, constant thickness from cheek to intrados over the half circumference on the intrados side, a linearly varying thickness between each cheek and extrados, as shown in Figure 2. Such characteristics have been found in feeder thickness inspections at various CANDU stations.

In this paper, it demonstrates that $C_{2}$ value for the minimum uniform thickness is higher than the value corresponding to the non-uniform thickness. Furthermore, piping analysis examples are given to show the comparison between the "average minimum - average" approach and finite element method conducted on non-uniform thickness bends.

This approach offers the flexibility of using a general piping software to conduct non-uniform wall thickness piping stress analysis with improved yet conservative results.

\subsection{STRESS INDEX $\mathrm{C}_{2}$ CALCULATION}

It is commonly known that formula $\left(\mathrm{C}_{2}=1.95 / \mathrm{h}^{2 / 3}\right)$ given by NB-3600 is conservative [Reference 2], especially for bend angle less than 90 degree. In order to accurately assess stress condition for degraded piping bends, it is essential to find more realistic $\mathrm{C}_{2}$ value by conducting detail finite element analysis.

Feeder pipes have non-90 degree compound bends, where two bends are closely spaced. See Figure $\mathbf{3}$ for a typical bend layout.

As per NB-3682 (a), the general definition of stress index $\mathrm{C}_{2}$ for mechanical loads is defined as:

$$
\mathrm{C}_{2}=\sigma / \mathrm{S}
$$

where: $\quad \mathrm{S}=$ nominal stress due to load $\mathrm{M}$

$\sigma=$ elastic stress due to load $\mathrm{M}$

In this paper, linear elastic finite element method is used, the stress index $C_{2}$ is determined as

$$
\mathrm{C}_{2}=\sigma_{\mathrm{m}+\mathrm{b}} / \mathrm{S}
$$

where $\sigma_{\mathrm{m}+\mathrm{b}}$ is the maximum membrane plus bending stress intensity calculated by finite element method on feeder bend models. In the past, the stress index was often determined by applying an in-plane bending, or an out-plane bending, even a torsional moment. In the case of compound bends, in which two bend do not lie in the same plane, a more general approach has to be implemented. The approach is described in following steps.

STEP 1 Apply “unit” moment $\mathrm{M}_{\mathrm{x}}=1000 \mathrm{~N}-\mathrm{mm}, \mathrm{M}_{\mathrm{y}}=1000 \mathrm{~N}-\mathrm{mm}$ and $\mathrm{M}_{\mathrm{z}}=1000 \mathrm{~N}-\mathrm{mm}$ loads in the global Cartesian coordinate system at one end of bend model in three load cases. See Figure $\mathbf{4}$ for moment loading diagram on a bend.

STEP 2 Using above three case results, and applying linear superposition principle to obtain stress results of loading cases other than the moment is applying only in the $\mathrm{x}, \mathrm{y}$ or $\mathrm{z}$ directions.

$$
\begin{aligned}
& \mathrm{M}_{\mathrm{r}_{-} \mathrm{x}}=\mathrm{M}_{\mathrm{r}} * \sin (\theta)=1000 * \sin (\theta) \\
& \mathrm{M}_{\mathrm{r}_{-} \mathrm{y}}=\mathrm{M}_{\mathrm{r}} * \cos (\theta) * \cos (\varphi)=1000 * \cos (\theta) * \cos (\varphi) \\
& \mathrm{M}_{\mathrm{r}_{-} \mathrm{z}}=\mathrm{M}_{\mathrm{r}} * \cos (\theta) * \sin (\varphi)=1000 * \cos (\theta) * \sin (\varphi)
\end{aligned}
$$

Therefore, a unit moment loading $\mathrm{M}_{\mathrm{r}}$ ( $=1000 \mathrm{~N}$-mm with direction of $\theta, \varphi$ ) should have following stress components at any node by superposing the three "unit" load results.

$$
\begin{aligned}
& \mathrm{S}_{11}=\left(\mathrm{S}_{11}\right)_{\mathrm{Mx}=1000} * \sin (\theta)+\left(\mathrm{S}_{11}\right)_{\mathrm{My}=1000} * \cos (\theta) * \cos (\varphi)+\left(\mathrm{S}_{11}\right)_{\mathrm{Mz}=1000} * \cos (\theta) * \sin (\varphi) \\
& \mathrm{S}_{22}=\left(\mathrm{S}_{22}\right)_{\mathrm{Mx}=1000} * \sin (\theta)+\left(\mathrm{S}_{22}\right)_{\mathrm{My}=1000} * \cos (\theta) * \cos (\varphi)+\left(\mathrm{S}_{22}\right)_{\mathrm{Mz}=1000} * \cos (\theta) * \sin (\varphi) \\
& \mathrm{S}_{33}=\left(\mathrm{S}_{33}\right)_{\mathrm{Mx}=1000} * \sin (\theta)+\left(\mathrm{S}_{33}\right)_{\mathrm{My}=1000} * \cos (\theta) * \cos (\varphi)+\left(\mathrm{S}_{33}\right)_{\mathrm{Mz}=1000} * \cos (\theta) * \sin (\varphi)
\end{aligned}
$$




$$
\begin{aligned}
& \mathrm{S}_{12}=\left(\mathrm{S}_{12}\right)_{\mathrm{Mx}=1000} * \sin (\theta)+\left(\mathrm{S}_{12}\right)_{\mathrm{My}=1000} * \cos (\theta) * \cos (\varphi)+\left(\mathrm{S}_{12}\right)_{\mathrm{Mz}=1000} * \cos (\theta) * \sin (\varphi) \\
& \mathrm{S}_{23}=\left(\mathrm{S}_{23}\right)_{\mathrm{Mx}=1000} * \sin (\theta)+\left(\mathrm{S}_{23}\right)_{\mathrm{My}=1000} * \cos (\theta) * \cos (\varphi)+\left(\mathrm{S}_{23}\right)_{\mathrm{Mz}=1000} * \cos (\theta) * \sin (\varphi) \\
& \mathrm{S}_{13}=\left(\mathrm{S}_{13}\right)_{\mathrm{Mx}=1000} * \sin (\theta)+\left(\mathrm{S}_{13}\right)_{\mathrm{My}=1000} * \cos (\theta) * \cos (\varphi)+\left(\mathrm{S}_{13}\right)_{\mathrm{Mz}=1000} * \cos (\theta) * \sin (\varphi)
\end{aligned}
$$

The principal stress $\sigma_{1}, \sigma_{2}$, and $\sigma_{3}$ are then obtained by solving the following cubic equation for the unknown $\sigma_{\mathrm{i}}$ :

$$
\left|\begin{array}{llc}
\mathrm{S}_{11}-\sigma_{\mathrm{i}} & \mathrm{S}_{12} & \mathrm{~S}_{13} \\
\mathrm{~S}_{12} & \mathrm{~S}_{12}-\sigma_{\mathrm{i}} & \mathrm{S}_{23} \\
\mathrm{~S}_{13} & \mathrm{~S}_{23} & \mathrm{~S}_{33}-\sigma_{\mathrm{i}}
\end{array}\right|=\quad=0
$$

Stress difference $\sigma_{12}, \sigma_{23}$, and $\sigma_{23}$ are defined as differences between two principal stresses:

$$
\sigma_{12}=\sigma_{1}-\sigma_{2}, \quad \sigma_{23}=\sigma_{2}-\sigma_{3}, \quad \sigma_{13}=\sigma_{1}-\sigma_{3}
$$

The stress intensity or Tresca stress $\sigma_{\mathrm{m}+\mathrm{b}}$ is the largest absolute membrane plus bending stresses. A program is written to find the maximum linearlized stress intensity $\left(\sigma_{\mathrm{m}+\mathrm{b}}\right)$ at each bend by systematically increasing angles of $\theta$ and $\varphi$. The maximum is then used to compute stress index by comparing the nominal stress.

STEP 3 Nominal stress is defined as:

$$
\mathrm{S}=\mathrm{D}_{\mathrm{o}} \mathrm{M}_{\mathrm{r}} / 2 \mathrm{I}
$$

where $\quad \mathrm{M}_{\mathrm{r}}=$ “unit” moment loading ( = $\left.1000 \mathrm{~N}-\mathrm{mm}\right)$

$\mathrm{D}_{\mathrm{o}}=$ pipe bend outside diameter

$\mathrm{I}=$ pipe bend moment of inertia

If the minimum and average bend thicknesses are used to calculate stress respectively, then

$$
\begin{aligned}
& I_{\min }=\frac{\pi}{64}\left[D_{o}^{4}-\left(D_{o}-2 * T_{\min }\right)^{4}\right] \\
& I_{a v g}=\frac{\pi}{64}\left[D_{o}^{4}-\left(D_{o}-2 * T_{a v g}\right)^{4}\right]
\end{aligned}
$$

Stress indices $\mathrm{C}_{2}$ for uniform minimum thickness profile $\left(\mathrm{C}_{2 \min }\right)$ and simplified thickness profile $\left(\mathrm{C}_{2 \text { simp }}\right)$ are calculated as follows:

$$
\begin{aligned}
& \mathrm{C}_{2 \min }=\frac{\text { Maximum } \sigma_{\mathrm{m}+\mathrm{b}} \text { for uniform minimum thickness profile }}{\text { Nominal stress for uniform minimum thickness profile }\left(\mathrm{S}_{\min }\right)}, \quad \mathrm{S}_{\min }=\frac{\mathrm{D}_{\mathrm{o}} * \mathrm{M}_{\mathrm{r}}}{2 \mathrm{I}_{\min }} \\
& \text { and } \\
& \mathrm{C}_{2 \text { simp }}=\frac{\text { Maximum } \sigma_{\mathrm{m}+\mathrm{b}} \text { for simplified thickness profile }}{\text { Nominal stress for average thickness in simplified thickness profile }\left(\mathrm{S}_{\mathrm{avg}}\right)}, \quad \mathrm{S}_{\mathrm{avg}}=\frac{\mathrm{D}_{\mathrm{o}} * \mathrm{M}_{\mathrm{r}}}{2 \mathrm{I}_{\mathrm{avg}}}
\end{aligned}
$$

3-D linear elastic finite element models for different feeder bends are developed using 20-node reduced integration elements (C3D20) in ABAQUS 6.6. Each model starts at the end fitting connection and extends through the first and the second bend. The end fitting between feeder and fuel channel is assumed to be anchored; the "unit" load of $1000 \mathrm{~N}$-mm is applied at the end of a straight pipe, which is extended from the second bend and has a length of at least 5 times outside diameter $D_{0}$ to eliminate end effects. In each model, there are 3 layers of elements in the wall thickness direction and 36 elements along the feeder bend circumferential direction for each layer. Along the feeder bend direction, the element aspect ratio is 1.0 in the bend region. The feature of "kinematic coupling" in ABAQUS was used at the end of the straight pipe, where the "unit" moment is applied at the center of the pipe. The pipe material is SA106 GR. B with corresponding modulus of elasticity of $203 * 10^{3} \mathrm{MPa}$. Pressure based minimum thicknesses, as per NB-3641, for 2” and 2.5” pipe are $2.75 \mathrm{~mm}$ and $3.33 \mathrm{~mm}$ respectively.

Total of 13 bend models were developed for different minimum and non-uniform thickness profiles. The stress indices $\mathrm{C}_{2 \mathrm{~min}}$ and $\mathrm{C}_{2 \text { simp }}$, which are corresponding to the uniform minimum thickness and simplified thickness respectively, are tabulated in Table 1. From the results, it can be concluded that

$$
\mathrm{C}_{2 \min }>\mathrm{C}_{2 \operatorname{simp}}
$$

Because the non-uniform thickness profile always has more material at the cross section, thus the above relation is selfevident. The calculations are only conducted on the simplified thickness profiles. For other type thickness profiles where no thickness is smaller than the minimum thickness used in $\mathrm{C}_{2 \min }$ calculation, the same conclusion should remain valid. 


\subsection{STRESS CALCULATED BY AVERAGE - MINIMUM - AVERAGE APPROACH}

In this approach, the average thickness is used to calculate loads or stiffness and moment of inertia, but the minimum thickness is used to calculate stress index in a general piping software.

Therefore

Stress calculated by the piping software $=\mathrm{C}_{2 \min } *$ nominal stress for average thickness

On the other hand,

Actual stress for the non-uniform thickness calculated by FEM $=\mathrm{C}_{2 \text { simp }}$ * nominal stress for average thickness

Because $\mathrm{C}_{2 \min }>\mathrm{C}_{2 \text { simp }}$

Thus, Stress calculated by the piping software > Actual stress calculated by FEM for a non-uniform thickness profile.

Hence, the use of the "average - minimum - average" approach is conservative for moment loads. In addition, since the $\mathrm{C}_{2 \min }$ is based on the uniform minimum thickness profile, i.e. the minimum thickness is assumed everywhere at the bends, thus the same minimum thickness can be anywhere once the code compliance check is satisfied. The application of the method provides the flexibility in disposition of any thinning locations at bends.

\subsection{THE CASE STUDY: COMPARISONS BETWEEN PIPING ANALYSIS AND FINITE ELEMENT ANALYSIS}

A feeder pipe model C07W is taken as the study case. The pipe nominal size is 2.5 inch of total length of approximately $11 \mathrm{~m}$ long. The pipe dimension reduces to 2.0 inch at the first two bends. The piping layout is shown in Figure 5 . The design pressure and temperature are $11.275 \mathrm{MPa}$ and $318.3^{\circ} \mathrm{C}$ respectively. The pipe is connected to header and fuel channel at two ends. The heated heavy water is transferred through this outlet feeder pipes from fuel channels to the header of the primary heat transport system. The thermal expansion stress at the first two bends is, in general, the limiting factor for the NB-3600 code compliance analysis, especially when the wall thickness is reduced by FAC at the first two bends. The remaining portion of the pipe beyond the first two bends is conservatively assumed at the nominal thickness values.

The case study is conducted with an in-house piping analysis program STANPIPES [Reference 3]. The program, similar to other general piping analysis software, has the flexibility to implement different thicknesses for stiffness and stress indices calculations.

As described above, the limiting stress for the first two tight bends is the thermal expansion stress, which is calculated by Equation (12) of NB-3650.

$$
\mathrm{C}_{2} \frac{\mathrm{D}_{\mathrm{o}}}{2 \mathrm{l}} \mathrm{M}_{\mathrm{i}} \leq 3 \mathrm{~S}_{\mathrm{m}} \quad \text { Equation (12) in NB }-3650
$$

For the current study, other stresses are well below code allowables, except for Equation (10). Equation (10), if it is not met, is substituted by Equation (12) and (13). The comparison is made on Equation (12) for the thermal expansion stress only.

Four analysis methods are used in the case study for the comparison purpose. The minimum and average thicknesses are assumed as $3.80 \mathrm{~mm}$ and $5.10 \mathrm{~mm}$ for the first two bends.

Case 1: $\quad$ Solid Finite Element Analysis: 20-node brick elements were used for the entire length of piping, where the first two bends are modeled with the non-uniform thickness profile, in which the extrados is $3.80 \mathrm{~mm}$, the cheekintrados-cheek thickness is $5.537 \mathrm{~mm}$. This simplified thickness profile, as shown in Figure 6, has an average thickness of $5.10 \mathrm{~mm}$. Because the thickness profile is precisely modeled, hence this analysis is assumed as the benchmark case. The analysis is conducted with ANSYS 11.0 software.

Case 2/3: Conventional Piping Analysis: uniform thickness of for the first two bends; two calculations were conducted on $3.80 \mathrm{~mm}$ and $5.10 \mathrm{~mm}$ respectively; stress indices are determined using ASME code formulas. The analyses are performed with STANPIPES piping software.

Case 4: “Average-Minimum-Average” Piping Analysis: the average thickness of $5.10 \mathrm{~mm}$ is used to calculate piping stiffness and moment of inertia, the minimum thickness of $3.80 \mathrm{~mm}$ is used to calculate stress index as described in Section 2 of this paper. The analysis is performed with STANPIPES piping software.

Case 5: "Average-Minimum-Average” Piping Analysis with specific thickness profile: similar to Case 4, but the stress indices $\mathrm{C}_{2}$ are calculated with the non-uniform thickness profile instead of uniform minimum thickness profile. 
The results of case study are presented in Table 2. It is found that:

- If conventional piping analysis is used, only the uniform thickness of $5.10 \mathrm{~mm}$ meets code allowables and fit for service, while $3.80 \mathrm{~mm}$ would fail the code compliance.

- If “Average-Minimum-Average” approach is used, a non-uniform thickness of minimum and average thickness of 3.80 and $5.10 \mathrm{~mm}$ combination is acceptable. The minimum thickness of $3.80 \mathrm{~mm}$ can be anywhere on the bends. The pipe is fit for service. The results are conservative compared with FEM benchmark results.

- If "Average-Minimum-Average” with specific thickness profile is used, the piping analysis results are closer to FEM benchmark results. The results ( 0.75 of allowable) indicate smaller thickness than $3.80 / 5.10 \mathrm{~mm}$ is acceptable to the thermal expansion stress allowable.

The “Average-Minimum-Average” approach could be useful for piping systems which may be difficult or extremely time consuming to create full FEM models, such as connected feeder pipes as shown in Figure 7 [Reference 4]. Realistic results can be obtained by applying stress indices of minimum thickness to piping analysis program. If non-uniform thickness profiles are known, the $\mathrm{C}_{2}$ calculated from the specific profiles can be used to generate even more accurate results. The stress index $\mathrm{C}_{2}$ is independent to the linkage between pipes, thus it can be calculated effectively.

\subsection{CONCLUSIONS}

The following conclusions can be drawn from this study:

1. By incorporating average thicknesses in stiffness and code equation checks; and minimum thickness in stress indices calculations, a general piping software can be used for piping system stress analysis with non-uniform thickness fittings, such as elbows. The lesser requirement for fitting acceptable thicknesses and the flexibility of thinning location could lead to considerable service life extension while maintain conservative margins.

2. By using stress index $\mathrm{C} 2$ calculated from non-uniform thickness profiles, the piping analysis results are close to FEM analysis results. The application of the approach in complicated piping layouts could be cost effective.

\subsection{ACKNOWLEDGEMENT}

This study is supported by Ontario Power Generation Inc. The authors would like to express their appreciation to Mr. J. Liu, A. Strzelczyk and other colleagues in the Department of Engineering Mechanics for their support in accomplishing the study.

\subsection{REFERENCES}

[1]. The American Society of Mechanical Engineers; “ASME Boiler And Pressure Vessel Code (1995 Edition including 1997 Addenda), Section III, Division 1, Subsection NB”.

[2]. Liu, T., Kumar, R., Saleem, M. A., and Usmani, S. A., "Stress Indices for Feeder Pipe Bends Based on Finite Element Analysis," ASME PVP-Vol. 388, 1998.

[3]. Manning, B. and Stevens, T.; “STANPIPES User’s Manual”; OPGI Document, Revision February, 2002.

[4]. Li, M.; Aggarwal, M. L; Meysner, A. and Micelotta, C.; “A Bend Thickness Sensitivity Study of CANDU Feeder Piping”, SMiRT 18, Beijing, August 7 -1 12, 2005.

Table 1 Stress Indices $C_{2 m i n}$ and $C_{2 s i m p}$ for Uniform and Simplified Thicknesses for 13 Feeder Bends

\begin{tabular}{|c|c|c|c|c|c|c|c|c|c|c|c|c|c|c|c|c|c|c|}
\hline \multirow[b]{3}{*}{ No. } & \multirow[b]{3}{*}{$\begin{array}{l}\text { Model } \\
\text { Name }\end{array}$} & \multirow[b]{3}{*}{$\begin{array}{l}\text { Size } \\
\text { (in) }\end{array}$} & \multirow{3}{*}{$\begin{array}{c}\text { Outside } \\
\text { Diameter } \\
D_{0}\end{array}$} & \multirow{2}{*}{\multicolumn{3}{|c|}{$\begin{array}{l}\text { Bend Thickness }(\mathrm{mm}) \\
\text { (Bend } 1=\text { Bend 2) }\end{array}$}} & \multirow{2}{*}{\multicolumn{4}{|c|}{\begin{tabular}{c|c} 
Bend 1 & Bend 2 \\
Maximum Tresca Stress (MPa) by FEA
\end{tabular}}} & \multirow{2}{*}{\multicolumn{2}{|c|}{$\begin{array}{l}\text { Nominal Stress under } \\
1000 \mathrm{~N} \text {-mm (MPa) }\end{array}$}} & \multicolumn{6}{|c|}{ Stress Index $C_{2}$ and ratio } \\
\hline & & & & & & & & & & & & & \multirow[b]{2}{*}{$\begin{array}{c}C_{2 \text { simp for }} \\
\text { non_uniform } \\
\text { profile }\end{array}$} & \multicolumn{2}{|l|}{ Bend 1} & \multicolumn{3}{|c|}{ Bend 2} \\
\hline & & & & Average & Minimum & \begin{tabular}{|l} 
Average/ \\
Minimum
\end{tabular} & $\begin{array}{l}\text { non- } \\
\text { uniform } \\
\text { profile }\end{array}$ & $\begin{array}{c}\text { uniform } \\
\text { minimum } \\
\text { thickness }\end{array}$ & $\begin{array}{l}\text { non- } \\
\text { uniform } \\
\text { profile }\end{array}$ & $\begin{array}{c}\text { uniform } \\
\text { minimum } \\
\text { thickness }\end{array}$ & $\begin{array}{c}\text { Average } \\
\text { Thickness }\end{array}$ & $\begin{array}{l}\text { Minimum } \\
\text { Thickness }\end{array}$ & & \begin{tabular}{|c|}
$C_{2 m i n}$ for \\
Uniform \\
Minimum \\
Thickness \\
\end{tabular} & $\mathrm{C}_{2 \min } / \mathrm{C}_{2 \operatorname{simp}}$ & $\begin{array}{c}C_{2 s i m p} \text { for } \\
\text { non_uniform } \\
\text { profile }\end{array}$ & \begin{tabular}{|c|}
$C_{2 \min }$ for \\
Uniform \\
Minimum \\
Thickness
\end{tabular} & $\mathrm{C}_{2 \min } / \mathrm{C}_{2 \mathrm{simp}}$ \\
\hline \begin{tabular}{|l|}
1 \\
\end{tabular} & F13E & 2.5 & 73.0 & 4.91 & 4.59 & 1.07 & 0.153 & 0.171 & 0.087 & 0.096 & 0.060 & 0.063 & 2.57 & 2.72 & 1.06 & 1.46 & 1.53 & 1.05 \\
\hline 2 & C13W & 2.5 & 73.0 & 5.13 & 4.78 & 1.07 & 0.161 & 0.182 & 0.175 & 0.201 & 0.058 & 0.061 & 2.80 & 2.99 & 1.07 & 3.04 & 3.30 & 1.09 \\
\hline 3 & C12E & 2.5 & 73.0 & 5.10 & 4.74 & 1.08 & 0.162 & 0.185 & 0.177 & 0.204 & 0.058 & 0.061 & 2.80 & 3.02 & 1.08 & 3.06 & 3.33 & 1.09 \\
\hline 4 & cogw & 2.5 & 73.0 & 4.63 & 4.29 & 1.08 & 0.187 & 0.213 & 0.207 & 0.241 & 0.063 & 0.067 & 2.99 & 3.20 & 1.07 & 3.31 & 3.62 & 1.09 \\
\hline 5 & C14E & 2.5 & 73.0 & 4.77 & 4.40 & 1.08 & 0.179 & 0.205 & 0.197 & 0.231 & 0.061 & 0.065 & 2.93 & 3.15 & 1.07 & 3.23 & 3.55 & 1.10 \\
\hline 6 & C11W & 2.5 & 73.0 & 4.85 & 4.41 & 1.10 & 0.173 & 0.205 & 0.191 & 0.231 & 0.060 & 0.065 & 2.87 & 3.15 & 1.10 & 3.17 & 3.55 & 1.12 \\
\hline 7 & C15W & 2.5 & 73.0 & 5.67 & 4.78 & 119 & 0.135 & 0.172 & 0.144 & 0.200 & 0.053 & 0.061 & 2.53 & 2.82 & 1.12 & 2.70 & 3.28 & 1.22 \\
\hline 8 & COTW & 2.0 & 60.3 & 3.44 & 2.80 & 1.23 & 0.342 & 0.491 & 0.375 & 0.571 & 0.121 & 0.144 & 2.83 & 3.41 & 1.21 & 3.10 & 3.97 & 1.28 \\
\hline 9 & F10W & 2.5 & 73.0 & 5.04 & 4.09 & 1.23 & 0.143 & 0.201 & 0.087 & 0.112 & 0.058 & 0.069 & 2.45 & 2.90 & 1.19 & 1.49 & 1.62 & 1.09 \\
\hline 10 & C08E & 2.5 & 73.0 & 4.38 & 3.50 & 1.25 & 0.189 & 0.283 & 0.244 & 0.339 & 0.065 & 0.079 & 2.89 & 3.59 & 1.24 & 3.73 & 4.30 & 1.15 \\
\hline 11 & $\mathrm{H} 12 \mathrm{~W}$ & 2.5 & 73.0 & 4.69 & 3.66 & 1.28 & 0.154 & 0.230 & 0.087 & 0.126 & 0.062 & 0.076 & 2.49 & 3.03 & 1.22 & 1.50 & 1.79 & 1.19 \\
\hline 12 & C10E & 2.5 & 73.0 & 5.39 & 4.19 & 1.29 & 0.143 & 0.220 & 0.154 & 0.251 & 0.055 & 0.068 & 2.58 & 3.24 & 1.26 & 2.78 & 3.70 & 1.33 \\
\hline 13 & C16E & 2.5 & 73.0 & 5.10 & 3.69 & 1.38 & 0.153 & 0.263 & 0.167 & 0.311 & 0.058 & 0.075 & 2.65 & 3.49 & 1.32 & 2.89 & 4.12 & 1.43 \\
\hline
\end{tabular}


Table 2 Equation (12) Stress Comparison

(among conventional piping analysis, proposed approach and solid finite element methods)

\begin{tabular}{|c|c|c|c|c|c|c|c|c|}
\hline \multirow{2}{*}{$\begin{array}{c}\text { Case } \\
\text { No. }\end{array}$} & \multirow[t]{2}{*}{ Calculation Method } & \multirow{2}{*}{$\begin{array}{c}\text { Bend Thickness } \\
(\mathrm{mm})\end{array}$} & \multicolumn{2}{|c|}{$\begin{array}{c}\text { Maximum Thermal } \\
\text { Expansion Stress (MPa) }\end{array}$} & \multirow{2}{*}{$\begin{array}{c}\begin{array}{c}\text { Maxium Stress } \\
\text { ratio }\end{array} \\
3 \mathrm{~S}_{\mathrm{m}}=357 \mathrm{MPa} \\
\end{array}$} & \multicolumn{2}{|c|}{$\mathrm{C}_{2}$} & \multirow[t]{2}{*}{ Description } \\
\hline & & & Bend 1 & Bend 2 & & Bend 1 & Bend 2 & \\
\hline 1 & $\begin{array}{l}\text { Solid Finite Element } \\
\text { (Benchmark) }\end{array}$ & \begin{tabular}{|c|} 
Non-uniform \\
thickness profile: \\
minimum $=3.8$ \\
average $=5.10$
\end{tabular} & 228 & 235 & 0.66 & na & na & $\begin{array}{l}\text { entire piping is modeled with } \\
\text { solid elements, bend using non- } \\
\text { uniform thickness }\end{array}$ \\
\hline 2 & \multirow{2}{*}{ Uniform thickness (Piping) } & 3.8 & 389 & 406 & 1.14 & \multirow{2}{*}{\multicolumn{2}{|c|}{$\begin{array}{l}\frac{1}{3.31} \\
2.64\end{array}$}} & \\
\hline 3 & & 5.1 & 310 & 323 & 0.90 & & & d \\
\hline 4 & $\begin{array}{c}\text { Average - Minimum - Average } \\
\text { (Piping) }\end{array}$ & \multirow{2}{*}{$\begin{array}{c}\text { Non-uniform } \\
\text { thickness profile: } \\
\text { minimum = 3.8, } \\
\text { average }=5.10\end{array}$} & 336 & 317 & 0.94 & 2.59 & 2.85 & $\mathrm{C}_{2}$ calculated as per Section 2 \\
\hline 5 & $\begin{array}{c}\text { Average - Minimum - Average } \\
\text { (Piping, thickness profile } \\
\text { specific) }\end{array}$ & & 269 & 230 & 0.75 & 2.07 & 2.07 & $\begin{array}{l}\mathrm{C}_{2} \text { calculated as per Section } 2 \\
\text { using simplifed thickness profile, } \\
\text { the same as Case } 1 .\end{array}$ \\
\hline
\end{tabular}

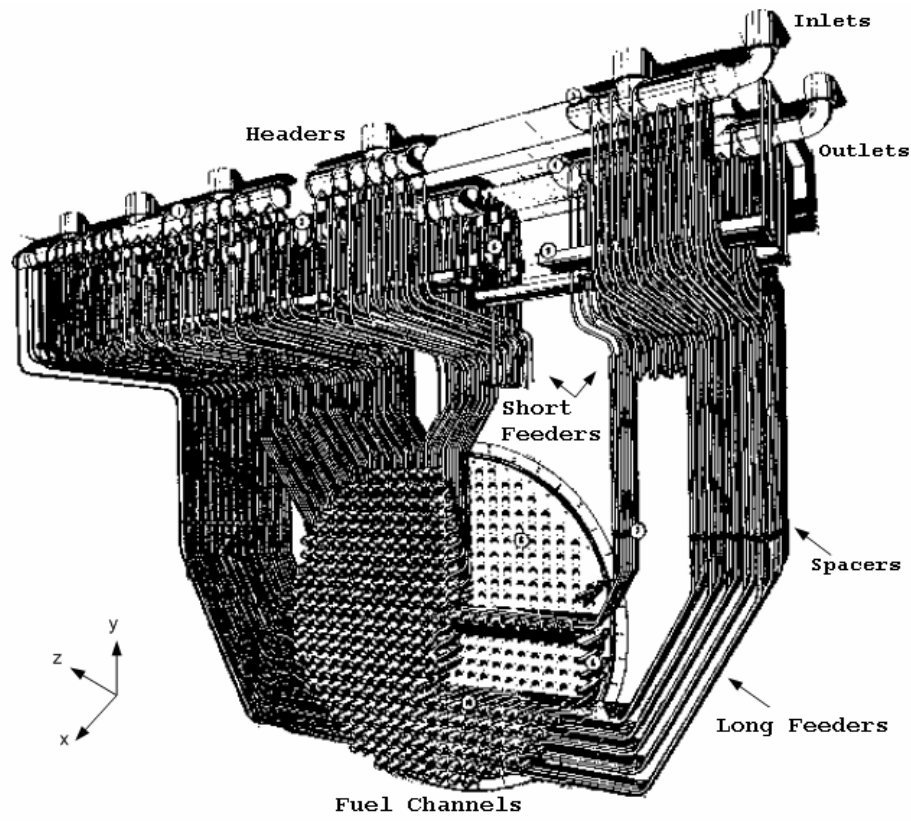

Figure 1 Typical CANDU Feeder Pipe Arrangement

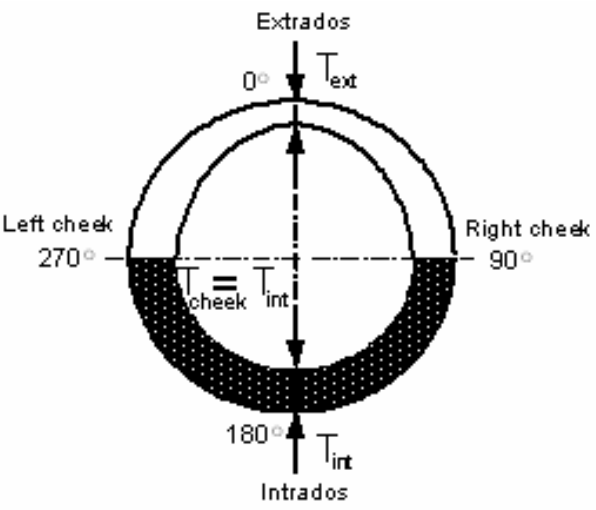

$T_{\text {avg }}=\left(3 T_{1 \mathrm{t}}+\mathrm{T}_{\mathrm{ext}}\right) / 4$

(where $T_{\text {ext }}$ - extrados thickness, equal to minimum $T_{\text {min }} ; T_{\text {cheek }}, T_{\text {int }}-$ cheek and intrados thickness)

Figure 2 Simplified Thickness Profile at a Degraded Pipe Bend 


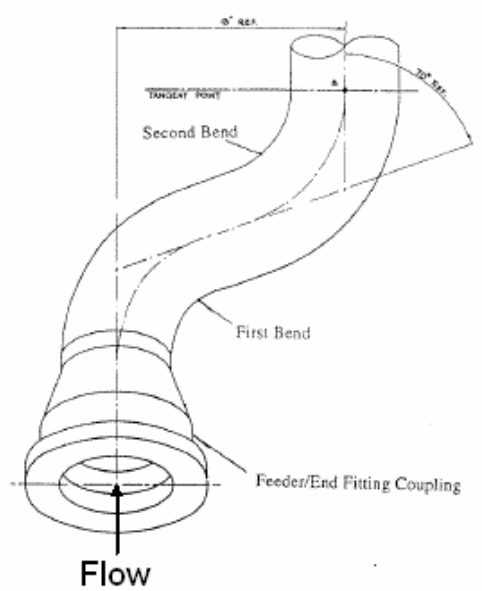

Figure 3 Typical Feeder Compound Bends

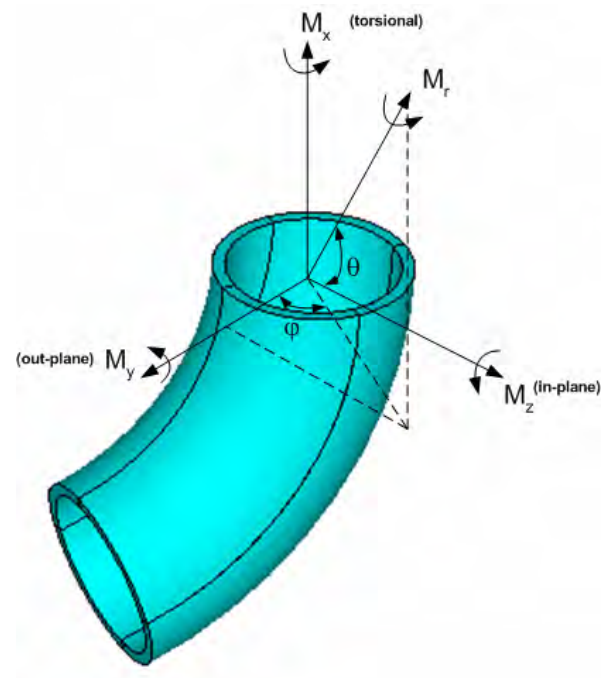

Figure 4 Moment Vector Loadings on a Bend

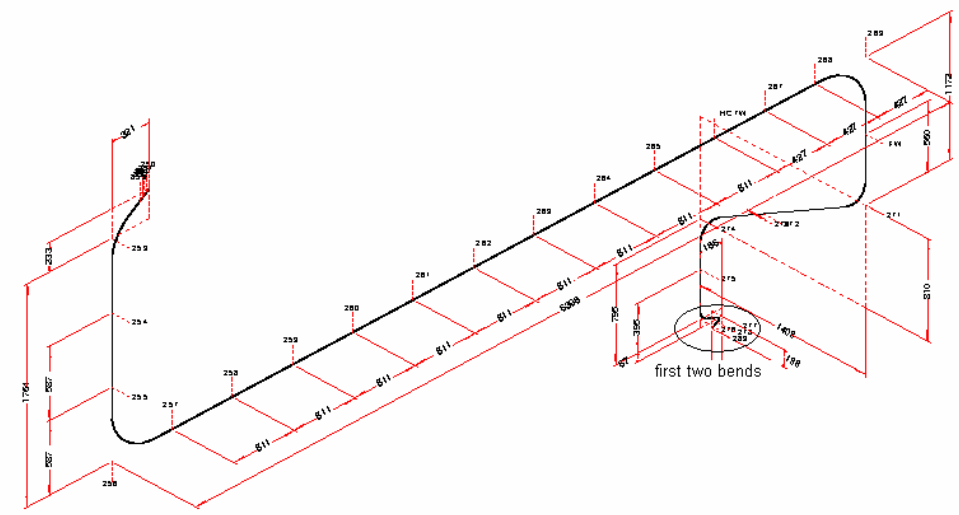

Figure 5 Piping Analysis Model for the Case Study (Model C07W - STANPIPES) 


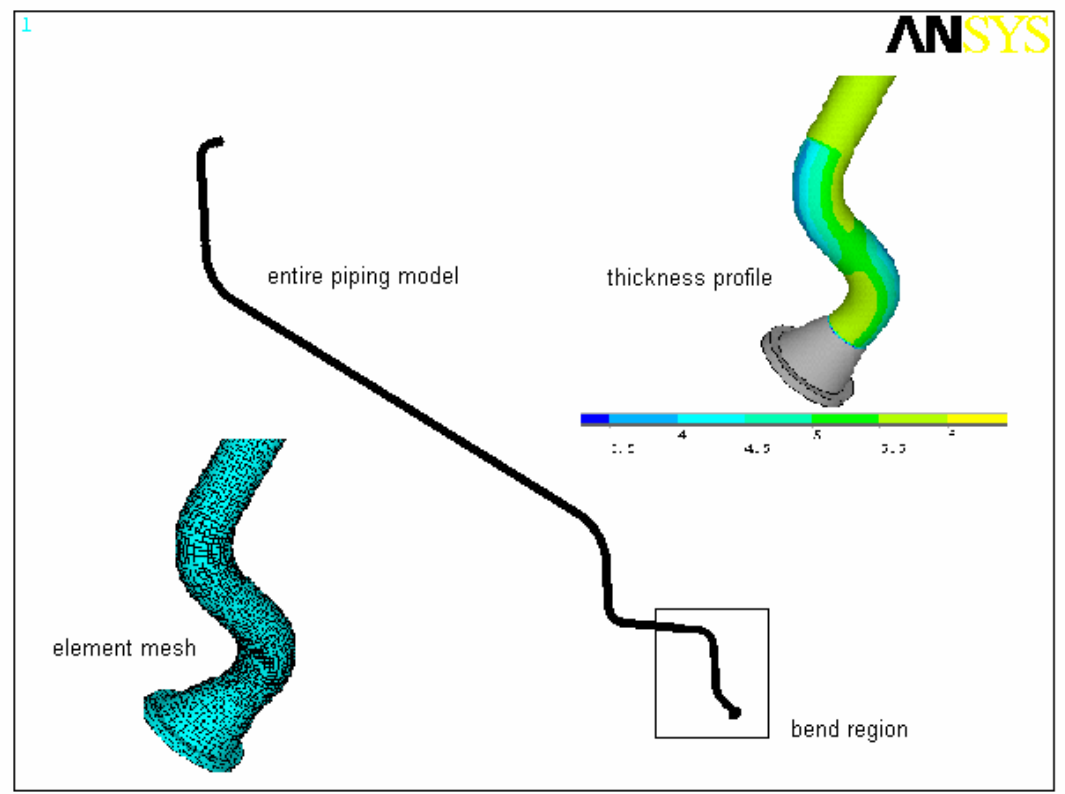

Figure 6 Finite Element Model for the Case Study - Thickness Profile and Mesh (C07W - ANSYS)

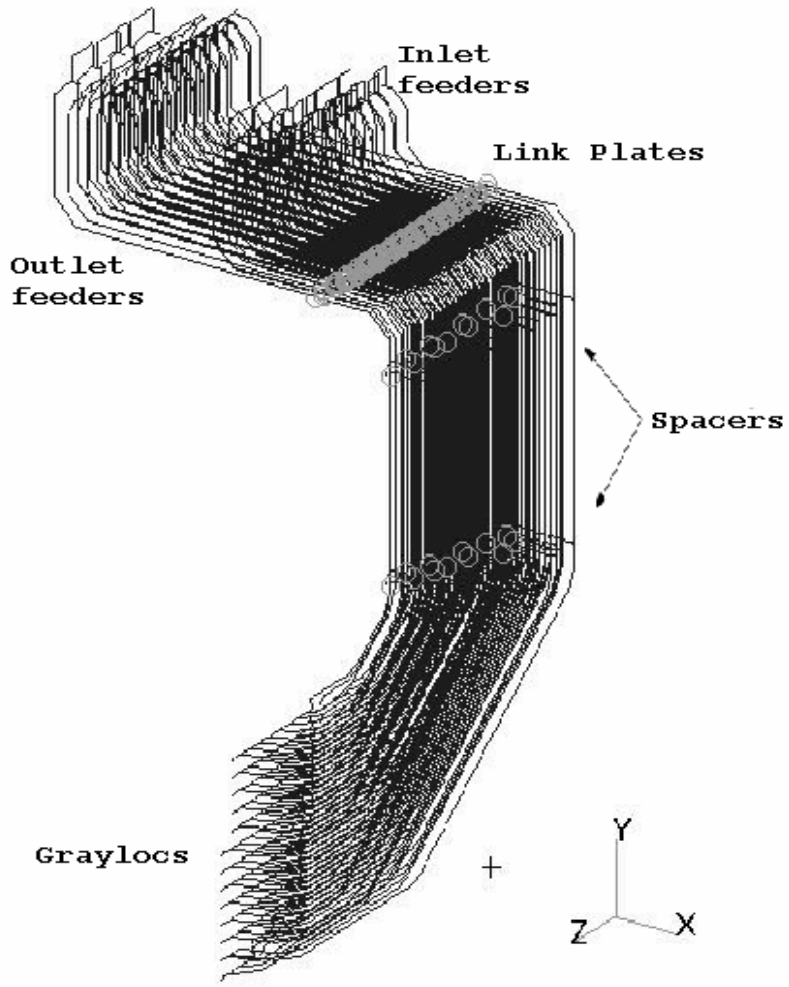

Figure 7 An Isometric View of a Linked CANDU Feeder Model [Reference 4] 